\title{
Monitoring change in land use and land cover in Rupnagar district of Punjab, India using Landsat and IRS LISS III satellite data
}

\author{
"Chander Kumar Singh, "Satyanarayan Shashtri, "Ram Avtar, \\ "Saumitra Mukherjee, ${ }^{* * *}$ Sudhir Kumar Singh
}

\author{
* Remote Sensing Applications Laboratory, School of Environmental Sciences, \\ Jawaharlal Nehru University, New Delhi, India, e-mail: dr.saumitramukherjee@usa.net \\ ${ }^{* *}$ Institute of Industrial Sciences, Department of Civil Engineering, \\ The University of Tokyo, Japan, 153-8505 \\ ${ }^{* * *}$ Department of Atmospheric \& Ocean Sciences, Nehru Science Centre Building, \\ Allahabad University, India, 211002
}

\begin{abstract}
Information about change is necessary for updating Land Use/ Land Cover LULC maps and the management of natural resources. The paper aims to map the changes in the LULC using hybrid classification methods and to quantify the land use/ land cover change that took place in the Rupnagar district of Punjab. The paper promotes the classification of LULC based on remote sensing information (obtained mainly through the utilization of Thematic Mapper TM) to generate data products that are both appropriate to, and immediately usable within different scientific applications. Satellite data provides the basis for geographically referenced land use/land cover characterization that is internally consistent, repeatable over time, and potentially more reliable. The main objective of this study is to quantify the change in the area of various LULC classes. Classification of four reflective bands of three Landsat images was carried out by using Isodata clustering algorithm with the aid of ground truth data. The second part focused on land use/ land cover changes by using the change detection comparison (pixel by pixel). The change analysis was performed by post image classification method, comparing the data from three different dates. The result indicates there was a rapid change in land use/land cover due to the increase in population. The results indicate that severe land cover changes have occurred in cropland $\left(225.97 \mathrm{~km}^{2}\right)$, dense forest $\left(128.57 \mathrm{~km}^{2}\right)$, settlement $\left(93.5 \mathrm{~km}^{2}\right)$, salt affected land $\left(9.74 \mathrm{~km}^{2}\right)$ and water body $\left(11.69 \mathrm{~km}^{2}\right)$ areas from 1989 to 2006 .
\end{abstract}

Key words: remote sensing, LULC, ISODATA, unsupervised classification, Landsat, IRS.

\section{Introduction}

Land use refers to how land is being used by humans while land cover is a measure of what is covering the surface of the earth (Jensen 2000). Understanding rate of land use changes in time and space and to find out the drivers behind this is very useful in preparing the model for the regional spatial pattern of this region and future prediction of implications of these changes. Information about change is necessary for updating land cover maps and the management of natural resources (XiaoMei \& RongQing 1999). Land Use and Land Cover (LULC) change is one of the most visible results of human modification of the terrestrial ecosystem and it has a significant impact on the local, regional, and global environment (Weng 2002). There is hardly an interaction between the atmosphere, biosphere and humans that is not affected by the type of LULC present on the earth surface. Multi-temporal satel- 
lite image composites are now of standard use in land cover classification of large areas at regional and global scales (Chen 2002). LULC and human/natural modifications have largely resulted in deforestation, biodiversity loss, global warming and increase of natural disaster-flooding (Dwivedi et al. 2005). These environmental problems are often related to LULC changes; therefore, available data on LULC change can provide critical input to decision-making of environmental management and planning the future. The growing population and increasing socio-economic necessities creates a pressure on LULC. This pressure results in unplanned and uncontrolled changes in LULC (Seto et al. 2002). Local LULC changes ranging from losses of wetlands, productive lands and biodiversity to expansion of croplands at the expense of forests across the world are one of the most important human induced disturbance that contribute to global environmental and climate change (Wali et al. 1999; Evrendilek \& Ertekin 2002; Kalnay \& Cai 2003). Change in LULC affects exchange of energy, water and momentum between the biosphere and atmosphere, as has been demonstrated by experiments which quantify the effects of changes in land use/land cover on climate. It also enhances the soil erosion, creates strong environmental impacts and high economic costs by its effect on agricultural production, infrastructure and water quality (Lal 1998; Pimentel et al. 1995). Remote sensing has proven to be cost effective tool for studying changes (Jensen 1996). It also provides synoptic coverage of areas of interest and facilitates optimal assessment and monitoring capabilities. These features make remote sensing an optimal tool for this type of study (Alexander \& Milazzo, 1973). Remote sensing provides data that are available in time series to study the dynamics of the area over long periods, which bridges mapping and monitoring gaps in understanding the environmental change (Mukherjee 1998, 2004). These specifications of remote sensing can therefore greatly contribute to local, regional as well as global mapping and monitoring of change in land use/land cover (King \& Delpont 1993; Siakeu \& Oguchi 2000).

The main objective of the present study is to understand rate of land use/land cover changes in time and space in Rupnagar district of Punjab. In order to achieve this objective, Landsat data acquired in 1989 and 2000 were used together with IRS LISS III of year 2006. The Iterative Self Organising Data Analysis Technique (ISODATA) algorithm was used to classify the images into 11 different classes.

\section{Study Area}

Rupnagar district, falls between north latitude $30^{\circ} 32^{\prime}$ and $31^{\circ} 24^{\prime}$ and east longitude $76^{\circ} 18^{\prime}$ and $76^{\circ} 55^{\prime}$ (Fig.1). Satluj is the most important river of Rupnagar district; it enters near Nangal the place where it leaves the Hima-

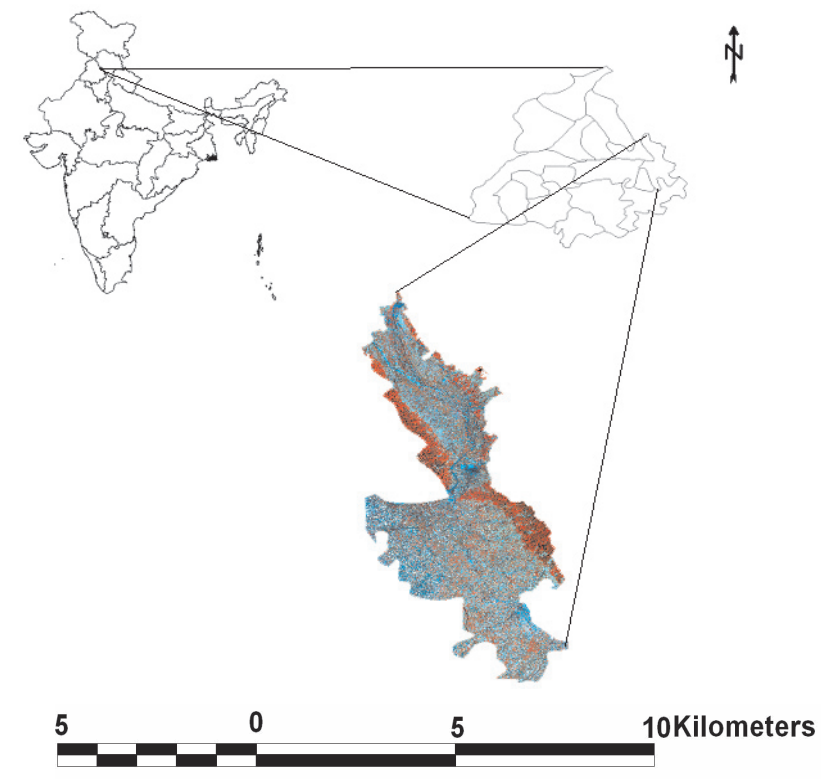

Figure 1. Study Area, Rupnagar district of Punjab, India

layas. From Nangal onwards, it flows sluggishly through Anandpur Dun for a distance of about 60 kilometers, leaving the dun through an opening across the Shiwalik Hills near Rupnagar and entering the Punjab plain. Although it is a perennial river, its discharge fluctuates widely with seasons. The potential of the river has been largely tapped for development of power and irrigation. A national project in the form of a gravity dam and reservoir has been established at Bhakra for generating hydroelectric power, dam at Nangal and barrages at Rupnagar and Harike divert the river water into canals. The Soan River and Sirsa River are the two major tributaries of the Satluj, which flow for short distance in the district before merging with the master stream.

Geologically, the rocks are disposed into two broad belts; outer and inner, formed of the upper and lower tertiary period. The rock formation found in the upper Shiwaliks consist of soft earth clay and boulder conglomerates. The middle Shiwaliks are composed of massive sand rock and clay beds. The lower Shiwalik have grey micaceous sand stones and slabs and are non-fossiliferous. The piedmont plain area is composed of the alluvium derived from these Shiwaliks intercepted by seasonal rivulets or choes.

The climate of Rupnagar District is characterized by its general dryness, a hot summer and a bracing cold winter. The average annual rainfall in district is $775.6 \mathrm{~mm}$. The soils of the district vary in texture generally from loam to silty clay loam except along the Satluj River where some sandy patches were found. 


\section{Material and method}

\subsection{Data and Image Analysis}

Landsat satellite image of year 1989, 2000 and IRS 1C LISS III satellite image of year 2006 were used in this study. Visible and infrared bands were included in the image analysis. The Figure 2 shows the methodology adopted for the study. Image classification applies to both postclassification and pre-classification change detection approaches and can be performed using either supervised or unsupervised approaches. In supervised classification, calibration data must be sufficiently sampled from appropriate areas and in unsupervised classification, an algorithm is chosen that will take remotely sensed image data set and find a pre-specified number of statistical clusters in measurement space (Schowengerdt 1997). Although these clusters must then be assigned to classes of land use/land cover, this method can be used without having prior knowledge of ground cover in the study site. The acquired satellite images of different time period were classified in software ERDAS 9.1. The images were classified by using hybrid classification techniques. In this particular type of classification spectral classes are grouped first, based solely on the numerical information in the data, and are then matched by the analyst to information classes. Unsupervised classifiers do not utilize training sets as the basis for classification it rather involves algorithms called clustering algorithms, in order to obtain the maximum information from satellite images used for image processing for LULC study.

The first approach used was the unsupervised classification where the classification is based on the aggregation of the classes depending on the spectral reflectance. The Iterative Self Organising Data Analysis Technique (ISODATA) was employed as a clustering algorithm. ISODATA requires relatively little human input to specify few criteria before running the algorithm. These steps are as follows: First step, specify the maximum number of clusters to be identified. Ten clusters were obtained, and then the number was reduced by splitting and merging of classes depending on the image spectral reflectance. Second step, identify the maximum percentage of pixels whose class values are allowed to be unchanged between iterations. The ISODATA algorithm terminates when this number is reached. Third step, specify the maximum number of iterations, where ISODATA classify in pixels and recalculate cluster mean vectors. Finally, specify the maximum standard deviation not to be exceeded during the classification.

In the first iteration, each candidate pixel is compared to each cluster mean and assigned to the cluster whose mean is closest in euclidean distance. During the second iteration, a new mean is calculated for each cluster based on the actual spectral locations of the pixels assigned to each cluster. After the new cluster mean vectors are selected,

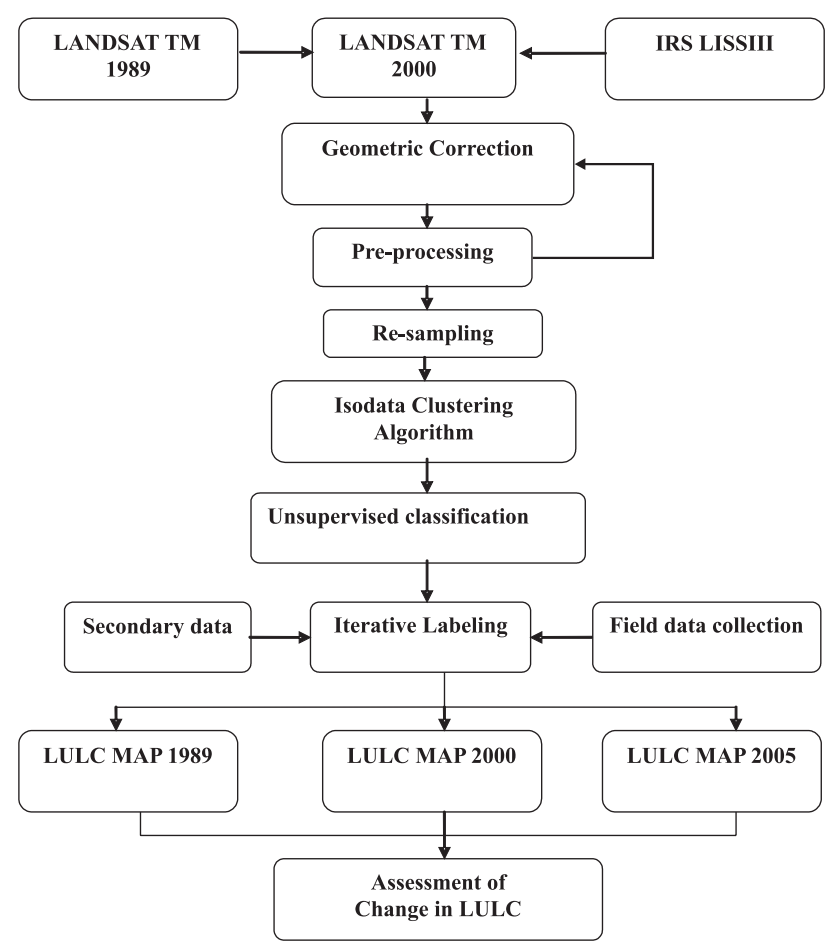

Figure 2. Flow chart of methodology

every pixel in the scene is once again assigned to one of the new clusters. The split and merge process continues until there is little change in class assignment between iterations, the threshold is reached or the maximum number of iteration is reached. Then the spectral classes were identified by comparing the classified image to ground truth points. The next step is to combine and label the spectral clusters into information classes.

\section{Results and discussions}

\subsection{Land Use and Land Cover}

In the current study the multi-temporal images were classified in eleven classes, except some other class relevant to the study, which was prominently observed, were also taken into account. The images were classified into following classes: 1 - river, 2 - canal, 3 - water body, 4 - cropland, 5 - fallow land, 6 - land with scrub, 7 - land without scrub, 8 - seasonal streams, 9 - dense forest, $10-$ salt affected land, 11 - settlement. The classes so created and the proportion of total area of the image covered by them, provide an insight into the composition of total area vis-à-vis the different features being represented by above mentioned classes. 

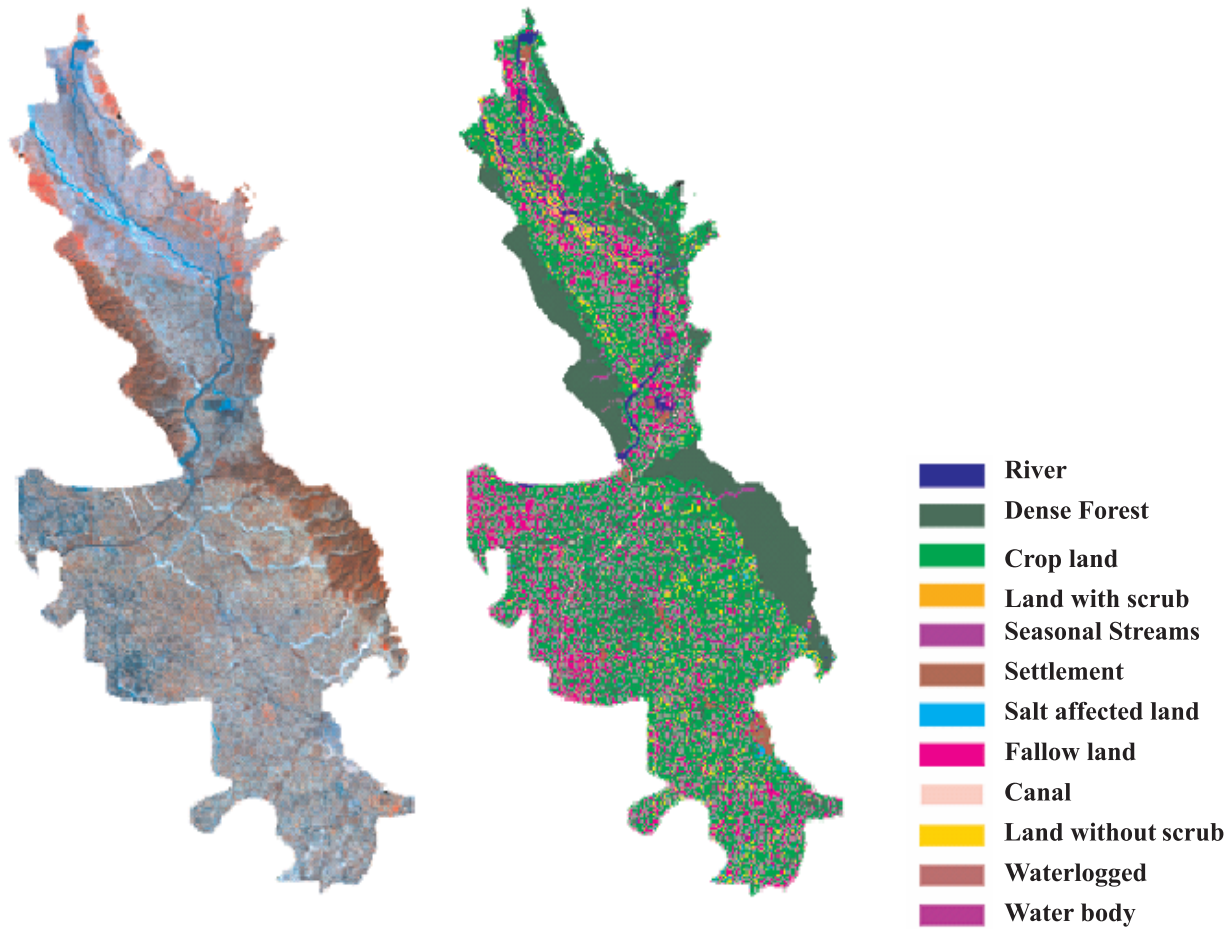

Figure 3. Landsat image of the year 1989 and its unsupervised classification
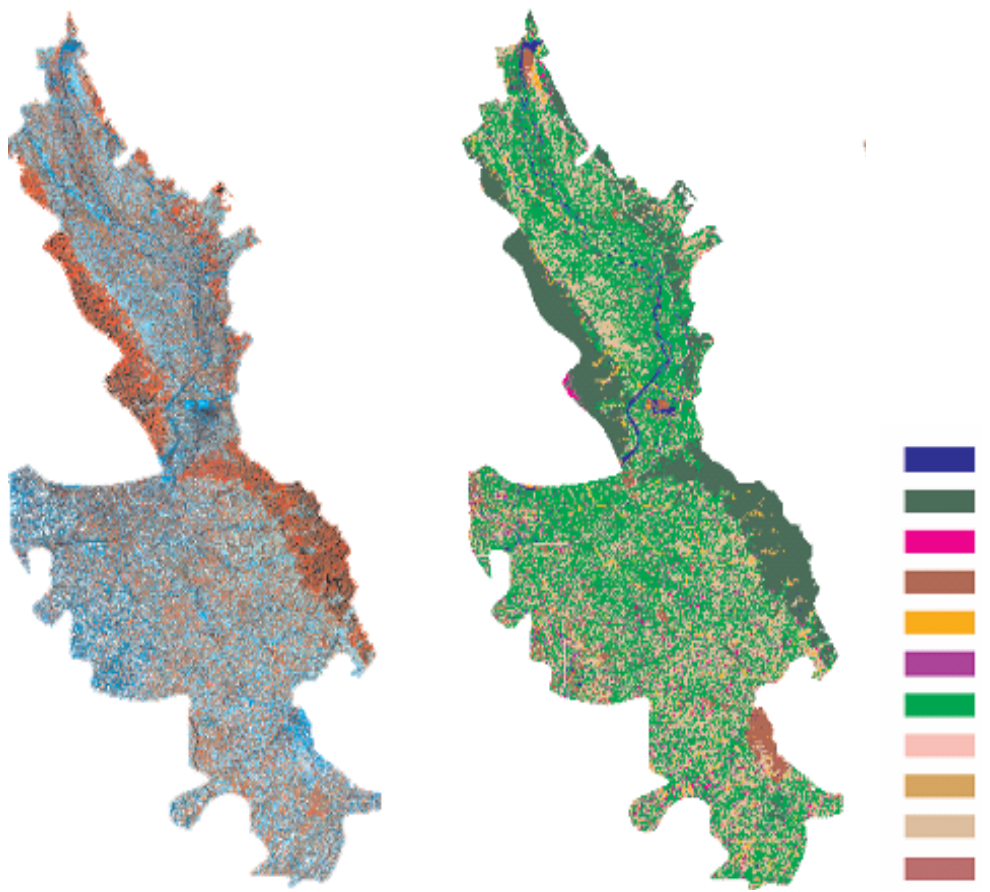

River

Dense Forest

Land without scrub

Settlemen

Seasonal

Salt affected land

Crop land

Canal

Water

Fallow

Land with scrub

Figure 4. Landsat image of the year 2000 and its unsupervised classification 

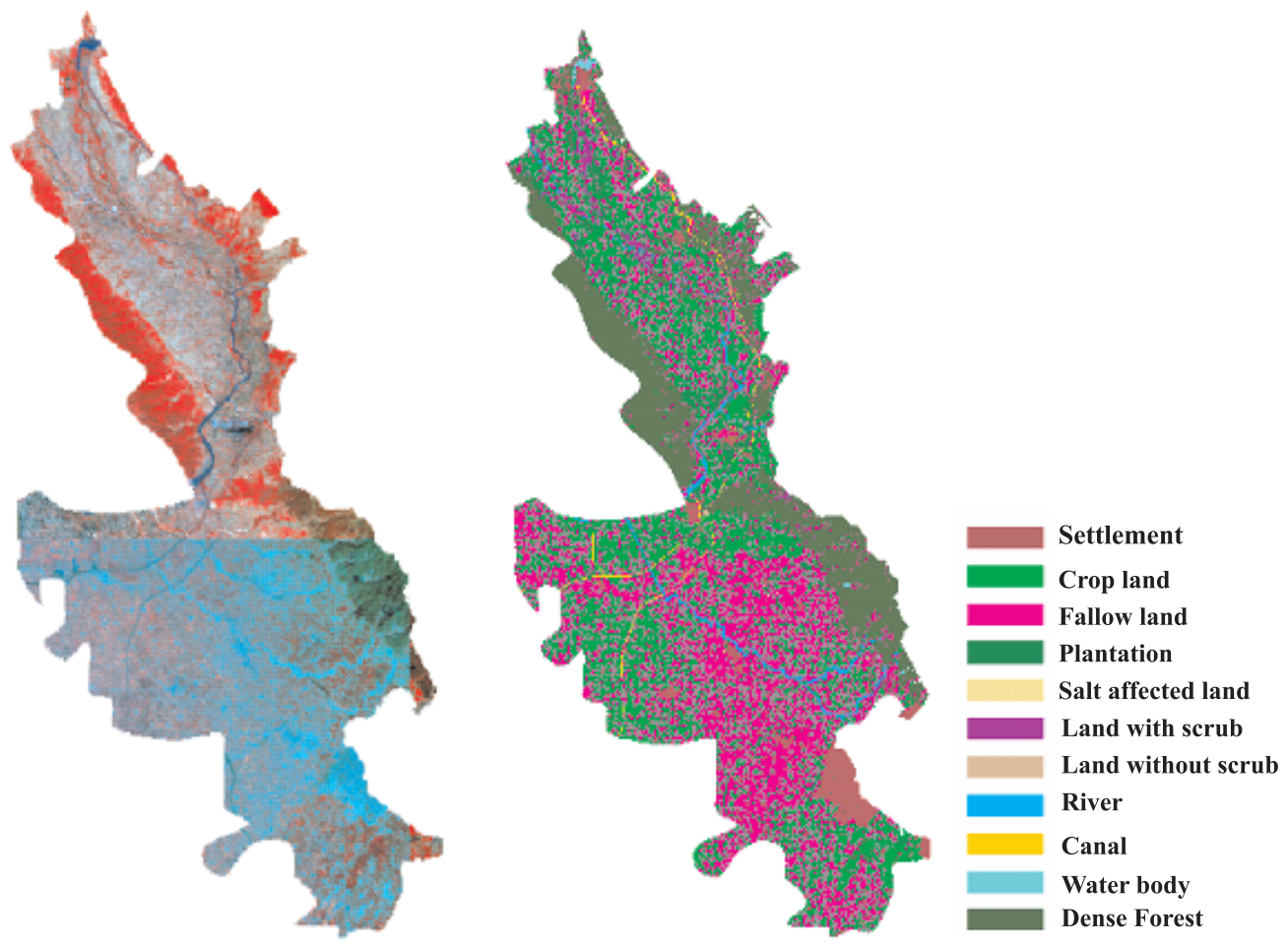

Figure 5. IRS IC LISS image of the year 2005 and its unsupervised classification

On account of analysis of these classified images, we are able to infer to a certain extent, the changes that occurred in the spatial composition with reference to the different physiographic features. In this regard when we compare the classified images of 1989 (Fig. 3) with that of 2000 (Fig. 4), we come across several such revelations. To start with we see that the area of the river as shown in the images of these two years shows a decrease by around $1.95 \mathrm{~km}^{2}$. On moving further we witness a phenomenal increase in the number of settlements, as much as to the tune of $60.39 \mathrm{~km}^{2}$, and this can easily be attributed to the increase of population. The cropland area shows a decrease of $89.61 \mathrm{~km}^{2}$, while the fallow land shows an increase of $112.98 \mathrm{~km}^{2}$. The decrease in cropland can thus be due to increase in settlement as well as due to increase in fallow land.

The area under dense forest cover shows a decrease of about $118.83 \mathrm{~km}^{2}$, which may also be correlated to the accompanying settlement and fallow land increase. Land with scrub displays an overwhelming rise of over $33.12 \mathrm{~km}^{2}$, while land without scrub on the other hand shows a decrease of around $3.9 \mathrm{~km}^{2}$. As we further analyze the classes, we find that the salt affected land is on the increase, to the tune of $5.84 \mathrm{~km}^{2}$, and this is basically due to the influence of Green Revolution in the region, leading to overuse of fertilizers which causes salinization due to excessive irri- gation means for which are provided by the canals in the region. On the contrary the comparison of area under water bodies throws up a different picture, it shows a decrease of around $3.9 \mathrm{~km}^{2}$. The seasonal streams area shows an increase of $11.69 \mathrm{~km}^{2}$, which may be due to the difference in the season when the image was actually taken.

In a similar way a comparison of classified images of 2000 and 2005 (Fig. 5) throws some light on the changes encountered in the various fields as a result of various interplaying factors in this decade. In this case the area under the river shows a negative trend as well, a decrease of around $3.9 \mathrm{~km}^{2}$, which is in consonance with the previous comparison. The settlement data signals an increase of around $33.12 \mathrm{~km}^{2}$, which is simple as the population increase was not high in this decade as was in the last one. The cropland, in this case shows a decrease of $136.36 \mathrm{~km}^{2}$, which again follows a trend similar to the one experienced in the last comparison. The fallow land here registers an increase of about $175.32 \mathrm{~km}^{2}$, and this coupled with an increase in the settlement area can be considered as primal causative factors in the earlier noticed trend of declining area under cropland. The dense forest cover in this case is also being affected by the accompanying enhanced anthropogenic influences, thereby registering a decrease of around $9.74 \mathrm{~km}^{2}$. Land with scrub is almost on the similar 


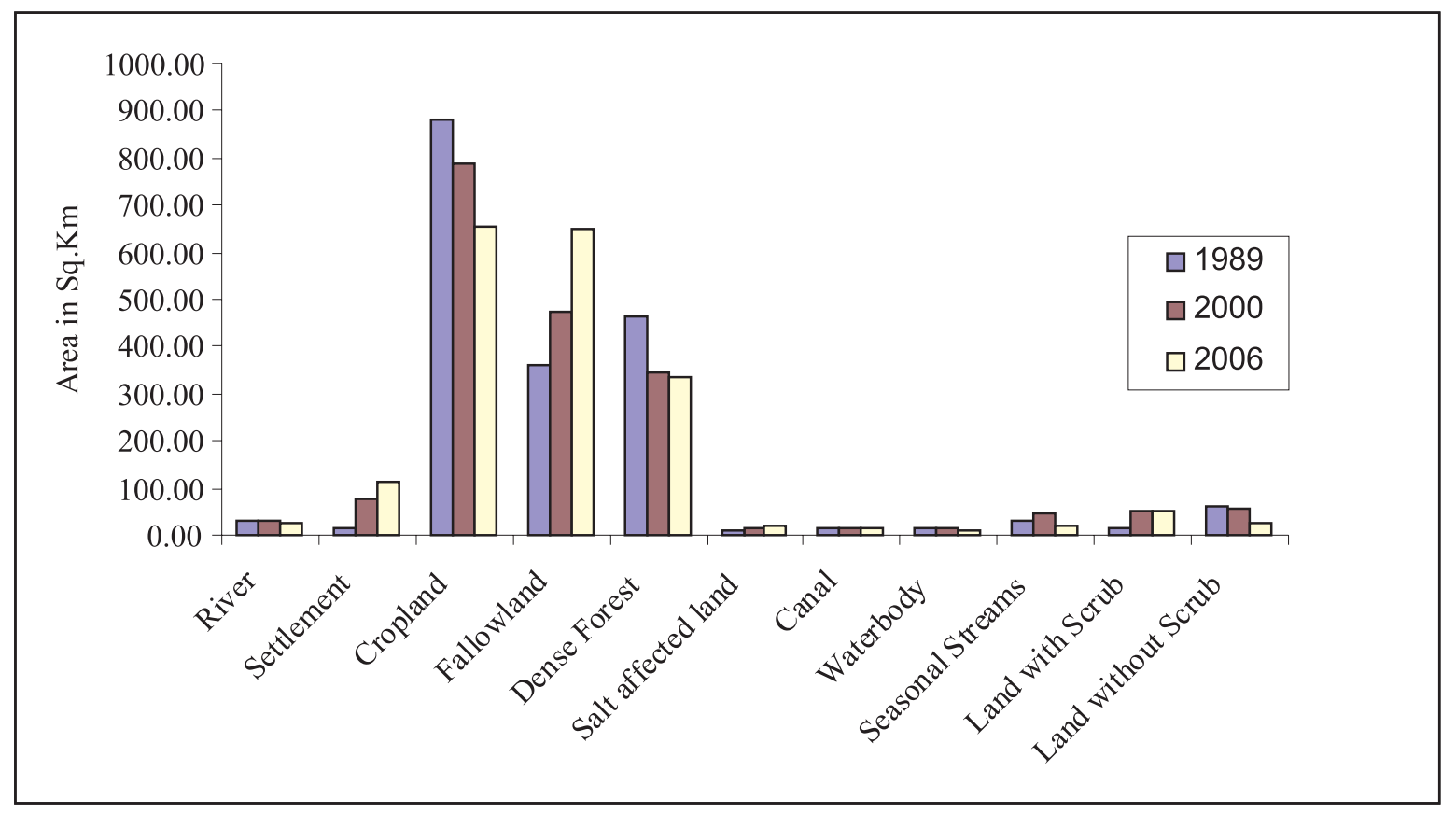

Figure 6. Bar diagram indicates the percentage of land use/land cover change in the study region during the year from 1989 to 2005.

scale as recorded earlier, not too significant decrease of $1.95 \mathrm{~km}^{2}$. Land without scrub has decreased quite significantly when we compare 2005 with 2000 , showing a decrease of around $35.06 \mathrm{~km}^{2}$. Here salt affected land here once again reflects more and more land being arrested by the influence of green revolution and consequent salinization due to excessive fertilization and consequently desired excessive irrigation. The decrease in water body area is also quite significant in 2005, as it falls by more than 1.95 $\mathrm{km}^{2}$ as compared to that in 2000. A similar trend is observed in seasonal streams although not to such an extent with it showing a decline of around $23.38 \mathrm{~km}^{2}$.

Now, if we take a holistic view of the available data and thus compare the different fields in the last two decades we observe that certain trends are not very encouraging from environmental viewpoint (Fig. 6). Primary among these are the trends displayed by area under river, dense forest, cropland and settlements. While there is a continuous decrease with the ultimate difference accruing to around $5.84 \mathrm{~km}^{2}$, $128.57 \mathrm{~km}^{2}$ and $225.97 \mathrm{~km}^{2}$ for river, dense forest and cropland respectively, the fourth field, which is settlement, has registered an alarming increase of $93.5 \mathrm{~km}^{2}$ (Fig. 5). All these factors when taken collectively do not augur well for the region on the environmental forefront. Fallow land, also shows an increase of $288.30 \mathrm{~km}^{2}$ but the reason can also be due to the different seasons in which the images were taken. The effect of gradually increasing influence of green revolution is continuously being manifested in the form of escalating area under salinization, the total increase being registered is around $9.74 \mathrm{~km}^{2}$. The area under water body as well as under seasonal streams displays a negative trend the total decrease being $5.84 \mathrm{~km}^{2}$ and $11.69 \mathrm{~km}^{2}$.

\section{Conclusion}

There is no substitute of development, but there is a great need to reduce or minimize the negative impacts of change in land use/land cover. The increase in cropland took place at the expense of irreversible losses of the lake and its related wetlands. The local extinction of wetland affects the other component of environment such as hydrological cycle, rate of infiltration, and change in local organic carbon. The losses of vital ecosystem goods and services were the result of change in land use/land cover. The result indicates that there was a great decrease in cropland and forest due to the rapid urbanization.

This study revealed that the regular monitoring with the help of remote sensing may serve as a very essential tool to assess the magnitude and rate of local environmental changes and to quantify interactions among local land use/land cover changes, and global climate change. The prospects of this study are in minimizing or reduction of environmental degradation, restoring damaged ecosystem for sustaining ecological goods and services. 


\section{Acknowledgements}

The author (CKS) thanks Satpal Mittal Trust for providing financial support to carry out the research work.

\section{References}

Alexander R. H. \& Milazzo V. A., 1973, Urban and regional land use analysis and census cities experiment package, MO, Progress Report E 74-1 0252, NASACR 1365661.

Chen X. W., 2002, Using remote sensing and GIS to analyze land cover change and its impacts on regional sustainable development, International Journal of Remote Sensing 23: 107-124.

Dwivedi R. S., Sreenivas K. \& Ramana K. V, 2005, Landuse/land-cover change analysis in part of Ethiopia using Landsat Thematic Mapper data, International Journal of Remote Sensing 2(7): 1285-1287.

Evrendilek F. \& Ertekin C., 2002, Agricultural sustainability in Turkey: integrating food, environmental and energy securities. Land Degradation \& Development 13(1): 61-67.

Jensen J. R., 1996, Introductory Digital Image Processing: a Remote Sensing Perspective, Second ed., Prentice Hall, Saddle River, NJ.

Jensen J. R., 2000, Remote Sensing of the Environment, Prentice-Hall Inc.

Kalnay E., Cai M., 2003, Impact of urbanization and land use change on climate, Nature 423: 528-531.

King C. \& Delpont G., 1993, Spatial assessment of erosion: contribution of remote sensing, a review, Remote Sensing Reviews 7: 223-232.

Lal R., 1998, Soil erosion impact on agronomic productivity and environment quality: Critical review, Plant Science 17: 319-464.
Mukherjee S., 1998, Change in groundwater environment with land use pattern in a part of south Delhi: A Remote Sensing approach, Journal of Asia-Pacific Remote Sensing and GIS 9(2): 9-14.

Mukherjee S., 2004, A text book of environmental remote sensing, Macmillan, India Ltd.

Pimentel D., Harvey C., Resosudarmo P., Sinclair K., Kurz D., McNair M., Crist S., Shpritz L., Fitton L., Saffouri R. \& Blair R., 1995, Environmental and economic costs of soil erosion and conservation benefits, Science: 2671117-2671123.

Schowengerdt R. A., 1997, Remote Sensing: Models and Methods for Image Processing, Second ed., Academic Press, San Diego, CA.

Seto K. C., Woodcock C. E., Song C., Huang X., Lu J. \& Kaufmann R.K., 2002, Monitoring land use change in the Pearl River Delta using Landsat TM, International Journal of Remote Sensing 23(10): 1985-2004.

Siakeu J. \& Oguchi T., 2000, Soil erosion analysis and modelling: a review, Transactions of the Japanese Geomorphological Union 21(4): 413-429.

Wali M. K., Evrendilek F., West T., Watts S., Pant D., Gibbs H. \& McClead B., 1999, Assessing terrestrial ecosystem sustainability: usefulness of regional carbon and nitrogen models, Nature \& Resources 35(4): 20-33.

Weng Q., 2002, Land use change analysis in the zhujiang delta of China using satellite remote sensing, GIS and stochastic modeling, Journal of Environmental Management 64: 273-284.

XiaoMei Y., \& RongQing L.Q.Y., 1999, Change Detection Based on Remote Sensing Information Model and its Application on Coastal Line of Yellow River Delta, Earth Observation Center, NASDA, China. 